\title{
Clustering effects of health risk behavior on mental health and physical activity in Chinese adolescents
}

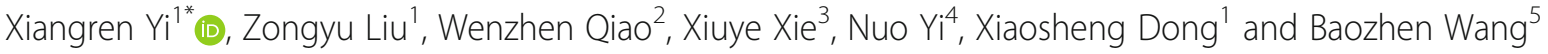

\begin{abstract}
Purpose: Risk behaviors are significantly impacting physical and psychological health among adolescents, resulting in a tremendous public health issue. The aim of this study is to examine the association of clustered risk behaviors with mental health and physical activity, and identify to what extent the clustering of various risk behaviors is associated with psychological health and physical activity in Chinese adolescents.

Methods: Students aged 16-18 years, male 16.2 \pm 1.03 , female $16.3 \pm 1.56$, were recruited from 30 high schools to complete an online questionnaire in fall semester 2017. A structured questionnaire, 2017 state and local youth risk behavior survey was revised, modified, and translated into Chinese. Five questions were designed to assess physical activity times of the last 7 days. Symptom checklist 90 (SCL-90) was used to investigate the mental health status of the participants. Statistical analyses were done employing chi-square tests, two step cluster analysis, logistic regression.

Result: Results illustrate that girls report a significantly higher mean of being bullied in school, electronically bullied, feeling sad or hopeless, and trying cigarette smoking. Two-step cluster analysis and regression analysis find that alcohol use, smoking and sedentary behavior have significant effect on adolescent health. Logic regression demonstrated that risk behaviors have significantly associated with mental health and physical activity in specific cluster.

Conclusion: This study finds that a specific behavior cluster has significant impact on mental health and physical activity among adolescents. Integrating risk behaviors cluster with factors can be employed to target high-risk adolescents who have poor physical and psychosocial health. The research suggest that more effective and feasible school intervention programs can be designed to promote adolescent health-related behavior in terms of those pathways.
\end{abstract}

Keywords: Risk behavior, Mental health, Physical activity, Adolescent

\footnotetext{
*Correspondence: xrenyi@163.com

'Department of Sport and Health, School of Physical Education, Shandong University, Jinan 250061, China

Full list of author information is available at the end of the article
}

C C The Author(s). 2020 Open Access This article is licensed under a Creative Commons Attribution 4.0 International License, which permits use, sharing, adaptation, distribution and reproduction in any medium or format, as long as you give appropriate credit to the original author(s) and the source, provide a link to the Creative Commons licence, and indicate if changes were made. The images or other third party material in this article are included in the article's Creative Commons licence, unless indicated otherwise in a credit line to the material. If material is not included in the article's Creative Commons licence and your intended use is not permitted by statutory regulation or exceeds the permitted use, you will need to obtain permission directly from the copyright holder. To view a copy of this licence, visit http://creativecommons.org/licenses/by/4.0/ The Creative Commons Public Domain Dedication waiver (http://creativecommons.org/publicdomain/zero/1.0/) applies to the data made available in this article, unless otherwise stated in a credit line to the data. 


\section{Instruction}

Risk behaviors are significantly impacting physical and psychological health among adolescents, resulting in a tremendous public health issue [1, 2]. Youth Risk behaviors are composed of extensive behaviors during the period of school, such as bullying [3], smoking [4] unhealthy diet [5], insufficient exercise [6] and harmful alcohol use [7], unintentional injuries and violence [8] etc., can cause physical diseases, psychosocial disorders [9-11], and premature illness [12]. Monitoring risk behaviors can assist the timely identification of potential preventive strategies [13]. Studies have demonstrated that the clustering of risk behaviors had a synergistic effect, changing one behavior's influence on other behaviors $[14,15]$. The preventive interventions that focus on simultaneously resolving clustered risk behaviors may be more effective and less costly $[9,13,15]$. Such intervention management depends on the health professional's knowledge of the clustering and features of a variety of risk behaviors.

It is realized that youth risk behavior clusters based on some theories or theoretical models have necessitated the increasing complication and comprehensiveness of risk behavior interventions research [16-18]. Conservation of resources (COR) theory indicated that risk and resilience issues cluster together and impact health, which may verify particularly valuable in considerate health-related resource caravan passageway $[19,20]$. The Lazarus \& Folkman's transactional theory of stress to explain that construction of some personal and social resources (self-esteem, self-efficacy, social support) performed as predictors of perceived stress level [21, 22]. Perceived stress should be associated with potential risk behaviors leading to onset of substance use and related risk behaviors heightened during the school period [23].

Traditional health-related behaviors study concentrated on the clustering of unhealthy diet, physical inactivity, sedentary time, and substance use [17, 24], but now includes more recent behaviors of internet use/screen time [16, $25]$, video gaming $[24,25]$ and bullying/being bullied [1, 26], all of which have become increasing physical and psychosocial health risks among adolescents.

Research on physical activity and mental health has been cognizant of various behavioral factors associated with physical fitness $[26,27]$. It is critical to identify the behavioral issues that are the most relevant correlates of physical activity. The findings have illustrated that actively encouraging youth to participate in more physical activity will reduce screen time in schools, communities and other settings, and promote psychosocial well-being [28]. Significant positive interactions have been identified among risk behaviors, physical inactivity, overweight and obesity, highlighting the importance of promoting physical activity and discouraging health-related risk behaviors in adolescent preventive intervention programs $[17,28]$.

Despite evidence showing associations among various risk behaviors, physical activity and mental health [29, 30], and the gender difference on suicidal ideation and its patterns with academic, family, social and health-risk factors as well [31].

little is known about the effects of risk behavior clustering on physical activity and psychological health, especially in China. Presently, among adolescents. The social competence, emotional and behavioral problem, and physical fitness status are serious issues among Chinese adolescents [32]. Therefore, it is essential to explore the interaction of a broad, comprehensive cluster of risk behaviors, physical activity and mental health for Chinese adolescents. The aim of this study is to examine the association of clustered risk behaviors with mental health and physical activity, and identify to what extent the clustering of various risk behaviors is associated with psychological health and physical activity in Chinese adolescents. The anticipated outcome of this study will be the increase of Chinese adolescents' physical activity and correspondingly the reduction of risky behaviors and the promotion of better psychological health in gender. On the basis of the findings, school intervention programs for health-related behaviors will be designed and developed for Chinese adolescents. This research explores detailed methods that can inform efficient future risk behavior interventions targeting adolescents.

\section{Methods}

\section{Participants and procedure}

Aged 16-18 years, 4630 students were randomly recruited from 30 high schools, to complete an online questionnaire in fall semester 2017. These schools were randomly chosen from 10 districts of Shandong Province, China. All students were assisted with the survey under the guidance of regional administrators, physical education teachers and graduate students. Students completed the questionnaire independently during physical education class. Students were informed that all data were collected voluntarily, anonymously and confidentially and maintained under a password-protected website, to be evaluated and processed only by the direct researchers. Parents and students filled out a consent form. The research was approved by the ethical committees of Shandong University, China.

\section{Measure}

A structured questionnaire was developed based on 2017 State and Local Youth Risk Behavior Survey [8] which was revised, modified, and translated into Chinese.

Reliability of the questionnaire was analyzed by Cronbach's alpha $(\alpha=0.72)$. Factor analysis had been performed 
to evaluate construct validity by the Kaiser-Meyer-Olkin $(\mathrm{KMO}=0.81)$ and Bartlett test $\left(\chi^{2}=2.2, p=0.00\right)$. Five questions were designed to assess physical activity times of the last 7 days, such as PE class, lunchtime, after school, evening, and weekend. Specifically, these five questions are "How often did you engage in strenuous exercise (vigorous play, running, jumping, throwing) in gym class over the past seven days?", "What have you usually been doing at lunch the past seven days (other than eating lunch)?", "In the past seven days, how many days have you been physically active after school to play sports, dance or do some vigorous exercise?", "In the past seven days, how many days in the evening have you been physically active doing exercise, dancing or something strenuous?", "How many times did you play sports dance or do some strenuous exercise last weekend.". The reliability is Cronbach's alpha $(\alpha=0.78)$. Symptom Checklist 90 (SCL-90) [33] was used to investigate the mental health status of the subjects, including 9 subscales: somatization, obsessive-compulsive symptoms, interpersonal sensitivity, depression, anxiety, hostility, terror, paranoia and psychosis. The reliability and validity of the Chinese version has been tested [34, 35].

\section{Statistical analysis}

Statistical analyses were done employing SPSS version 26 (IBM, Chicago, IL, USA). Descriptive statistics were calculated for all characteristics in term of gender, risk behaviors, mental health and physical activity. The numerical variables were articulated as mean and standard deviation (mean $\pm \mathrm{sd}$.) Chi-square tests were utilized to compare the proportion of screen time, smoking, drinking, alcohol, bullying and sedentary behaviors. Two Step Cluster Analysis (TCA) was employed to analyze groups of adolescents with similar behaviors. Logistic regression was performed to assess the association among clustered behavioral factors, mental health and physical activity variables and to identify odds ratio (OR) and the corresponding 95\% confidence intervals (CI).

\section{Results}

\section{Comparison of risk behaviors}

A total of 4630 students participated in this survey, male 2199 (47.5\%), female 2431(52.5\%), aged 16-18 years, male $16.2 \pm 1.03$, female $16.3 \pm 1.56$. Table 1 shows the characteristics of the male and female participants and the comparison of their risk behavior. Results illustrate that girls report a significantly higher mean of being bullied in school $\left(\mathrm{x}^{2}=\right.$ 41.78, $p<0.01)$, electronically bullied $\left(x^{2}=74.25, \mathrm{p}<0.01\right)$, feeling sad or hopeless $(\mathrm{x} 2=74.25, \mathrm{p}<0.01)$, and trying cigarette smoking $(\mathrm{x} 2=74.25, p<0.01)$, but boys have a significantly higher mean in other items. The physical activity is not mean different between boys and girls (Table 1).

\section{Factor analysis}

Factor analysis was performed for risk behaviors, both the KMO $(0.8)$ and Bartlett test of sphericity $(p<0.001)$

Table 1 Gender differences in risk behavior, physical activity and mental health

\begin{tabular}{|c|c|c|c|c|}
\hline & Male & Female & $x^{2}$ & $P$ \\
\hline Watch TV & $1.68 \pm 1.35$ & $1.41 \pm 1.05$ & 69.79 & 0.00 \\
\hline Play video or computer games & $2.14 \pm 1.56$ & $1.73 \pm 1.24$ & 1.06 & 0.00 \\
\hline Use smart phone & $2.68 \pm 1.55$ & $2.59 \pm 1.60$ & 35.48 & 0.00 \\
\hline Use iPad & $3.64 \pm 1.37$ & $3.69 \pm 1.33$ & 5.22 & 0.00 \\
\hline Bullied in school & $1.87 \pm 0.33$ & $1.94 \pm 0.23$ & 74.25 & 0.00 \\
\hline Electronically bullied & $1.88 \pm 0.33$ & $1.93 \pm 0.25$ & 40.13 & 0.00 \\
\hline Feel sad or hopeless & $1.81 \pm 0.39$ & $1.86 \pm 0.35$ & 19.49 & 0.00 \\
\hline Try cigarette smoking & $1.76 \pm 0.43$ & $1.92 \pm 0.28$ & 2.21 & 0.00 \\
\hline Age when first tried cigarette smoking & $2.12 \pm 1.93$ & $1.32 \pm 1.10$ & 3.23 & 0.00 \\
\hline Number of days smoking cigarettes & $1.40 \pm 1.22$ & $1.09 \pm 0.56$ & 1.73 & 0.00 \\
\hline Number of cigarettes each day & $1.27 \pm 1.13$ & $1.03 \pm 0.65$ & 1.44 & 0.00 \\
\hline At least one drink of alcohol & $2.53 \pm 2.18$ & $1.71 \pm 1.67$ & 2.87 & 0.00 \\
\hline Age of first drink of alcohol & $2.78 \pm 2.26$ & $1.90 \pm 1.82$ & 2.55 & 0.00 \\
\hline Ride in a car with somebody drinking alcohol & $1.24 \pm 0.77$ & $1.11 \pm 0.50$ & 41.78 & 0.00 \\
\hline At least one drink of alcohol & $1.75 \pm 1.67$ & $1.32 \pm 1.19$ & 1.58 & 0.00 \\
\hline At least exercise 60 min per day & $4.16 \pm 2.63$ & $3.91 \pm 2.59$ & 20.2 & 0.01 \\
\hline Physical education class & $2.67 \pm 1.29$ & $2.61 \pm 1.16$ & 26.49 & 0.00 \\
\hline Sports teams & $1.61 \pm 0.90$ & $1.50 \pm 0.79$ & 24.68 & 0.00 \\
\hline aHad a concussion & $1.62 \pm 1.07$ & $1.48 \pm 0.96$ & 24.16 & 0.00 \\
\hline
\end{tabular}

${ }^{2}$ During the past 12 months, how many times did you have a concussion from playing a sport or being physically active? 
Table 2 Factor analysis of risk behaviors

\begin{tabular}{|c|c|c|c|c|c|}
\hline & Factor1 & Factor 2 & Factor 3 & Factor4 & Factor5 \\
\hline Watch TV & 0.72 & & & & \\
\hline Play video or computer games & 0.6 & & & & \\
\hline Use smart phone & 0.42 & & & & \\
\hline Use iPad & 0.38 & & & & \\
\hline At least one drink of alcohol & & 0.81 & & & \\
\hline Age of first drink of alcohol & & 0.72 & & & \\
\hline Ride in a car with somebody drinking alcohol & & 0.64 & & & \\
\hline At least one drink of alcohol & & 0.61 & & & \\
\hline Tried cigarette smoking & & & 0.79 & & \\
\hline Age when first tried cigarette smoking & & & -0.79 & & \\
\hline Days of cigarettes smoking & & & 0.66 & & \\
\hline Number of cigarettes each day & & & 0.65 & & \\
\hline Electronically bullied & & & & 0.73 & \\
\hline Feel sad or hopeless & & & & 0.68 & \\
\hline Bullied in school & & & & 0.66 & \\
\hline At least exercise 60 min per day & & & & & 0.72 \\
\hline Physical education class & & & & & 0.66 \\
\hline Sports teams & & & & & 0.57 \\
\hline Had a concussion & & & & & 0.42 \\
\hline Eigenvalue & 4.26 & 1.83 & 1.69 & 1.17 & 1.08 \\
\hline Variance explained \% & 4.26 & 9.63 & 8.88 & 6.15 & 5.66 \\
\hline Cumulative variance explained \% & 14.62 & 24.88 & 35.09 & 44.52 & 52.79 \\
\hline
\end{tabular}

$\mathrm{KMO}=.805$ ( $\mathrm{KMO} \geq .60$ means that the result of the factor analysis is acceptable) Bartlett's test of sphericity: $\mathrm{X} 2=2.2(\mathrm{df}=171 ; p=.00)$

fit for the requirements (Table 2). Results of factor analysis identified that five behavioral patterns were separated for the individual behaviors. The five factors explained approximately $52.79 \%$ of variance of the nineteen items. Table 2 presented factor loadings and explained variance. Five main components were refined, mainly distributing (1) problematic screen time (videogames, smartphone, internet, iPad etc.); (2) drinking of alcohol (underage and binge drinking); (3) smoking (underage and smoke cigars days); (4) bully behaviors (bullying and being bullied); (5) sedentary behavior (insufficient physical exercise, long study time).

Table 3 Clusters of risk behavior formed by Two Step Cluster analysis

\begin{tabular}{lllll}
\hline & Cluster1 & Cluster2 & Cluster3 & Cluster4 \\
\hline Factor1 & 0.25 (low) & -0.30 (low) & 0.44 (medium) & 0.43 (medium) \\
Factor 2 & 0.67 (high) & 0.03 (normal) & -0.12 (low) & 0.11 (low) \\
Factor 3 & 0.20 (low) & -0.19 (low) & 0.60 (high) & 0.04 (normal) \\
Factor 4 & 0.33 (low) & 0.16 (low) & -0.55 (medium) & 0.17 (low) \\
Factor 5 & -0.78 (high) & 0.70 (high) & 0.55 (medium) & 0.20 (low) \\
\hline
\end{tabular}

\section{Cluster analysis}

Two-step Cluster Analysis (TCA) identifies four clusters in risk behaviors that details are presented in Table 3 . The regression analysis shows that cluster 1 contains the unhealthiest scores in factor 2 and factor 5 behavioral patterns. Cluster 2 and cluster 3 indicate two high risk behavior patterns in factor 3 and factor 5 . The results demonstrate that alcohol use, smoking and sedentary behavior have significant effect on adolescent health. Factor 1 are also relatively healthy behavior patterns, but three clusters are in a medium position. Factor 5 contains two high cluster and one medium cluster, meaning that sedentary behavior significantly affects student health.

\section{Analysis of risk behavior and mental health within cluster and factor}

Logic regression demonstrated the relationship between risk behavior and mental health based on the different variables (Table 4). In somatization, compared with cluster 1 in factor 1 , the odds ratios (ORs) and 95\% confidence intervals (CIs) were 0.97(0.83-1.13), 1.01(0.91$1.11)$ and $0.99(0.85-1.16)$ for cluster 2 , cluster 3 , cluster 4 , respectively. In the hostility category, compared with 
Table 4 Odd ratios (ORs) of the cluster risk behavior and mental health from ordered logistic model

\begin{tabular}{|c|c|c|c|c|c|c|}
\hline & & $\mathrm{F} 1$ & $\mathrm{~F} 2$ & F3 & F4 & F5 \\
\hline \multirow[t]{4}{*}{ Somatization } & $\mathrm{C} 1$ & Ref & & & & \\
\hline & $\mathrm{C} 2$ & $0.97(0.83-1.13)$ & $0.91(0.84-1.00)^{*}$ & $1.11(0.98-1.25)^{*}$ & $0.96(0.86-1.06)$ & $1.17(1.07-1.26)$ \\
\hline & $\mathrm{C} 3$ & $1.01(0.91-1.11)$ & $0.97(0.86-1.10)$ & $1.00(0.84-1.21)$ & 1.03(0.89-1.19) & $1.05(0.97-1.14)$ \\
\hline & C4 & $1.01(0.93-1.10)$ & $0.99(0.90-1.08)$ & $0.95(0.81-1.10)$ & $0.89(0.761 .04)$ & $1.05(0.96-1.15)^{* * *}$ \\
\hline \multirow[t]{4}{*}{ Obsessive-compulsive } & $\mathrm{C} 1$ & Ref & & & & \\
\hline & $\mathrm{C} 2$ & $0.97(0.83-1.14)$ & $0.95(0.87-1.03)^{* *}$ & $1.06(0.94-1.19)$ & $0.97(0.88-1.08)$ & 1.07(0.99-1.16) \\
\hline & $\mathrm{C} 3$ & $1.00(0.90-1.11)$ & $1.07(0.95-1.21)$ & $1.03(0.86-1.24)^{* *}$ & $1.07(0.93-1.23)$ & $1.10(1.02-1.19)^{* * *}$ \\
\hline & C4 & $0.97(0.89-1.05)$ & $0.94(0.86-1.03)$ & $1.02(0.88-1.19)$ & $1.01(0.86-1.18)^{*}$ & $1.04(0.95-1.14)$ \\
\hline \multirow[t]{4}{*}{ Interpersonal sensitivity } & $\mathrm{C} 1$ & Ref & & & & \\
\hline & $\mathrm{C} 2$ & $0.83(0.80-1.08)$ & $1.10(0.80-1.11)^{* *}$ & $1.03(0.85-1.30)$ & $1.10(0.90-1.21)$ & $0.89(0.80-1.18)$ \\
\hline & $\mathrm{C} 3$ & $1.16(0.85-1.30)$ & $1.14(0.89-1.32)$ & $1.02(0.73-1.38)^{* *}$ & $1.12(0.96-1.32)^{* *}$ & $1.25(0.93-1.70)$ \\
\hline & $\mathrm{C} 4$ & $0.92(0.83-1.15)$ & $1.13(0.86-1.21)$ & $1.16(0.80-1.38)$ & $1.00(0.85-1.21)$ & $1.04(0.79-1.57)$ \\
\hline \multirow[t]{4}{*}{ Depression } & $\mathrm{C} 1$ & Ref & & & & \\
\hline & $\mathrm{C} 2$ & $0.98(0.84-1.15)$ & $0.96(0.89-1.05)$ & $1.06(0.94-1.20)^{*}$ & $1.00(0.90-1.11)$ & $1.04(0.96-1.13)$ \\
\hline & $\mathrm{C} 3$ & $1.03(0.92-1.14)$ & $1.03(0.911 .17)^{*}$ & $0.99(0.82-1.19)$ & $1.11(0.961 .28)$ & $1.07(0.98-1.16)^{* *}$ \\
\hline & C4 & $0.97(0.89-1.05)$ & $0.98(0.89-1.07)$ & $1.01(0.87-1.18)$ & $1.04(0.88-1.22)$ & $1.05(0.95-1.15)$ \\
\hline \multirow[t]{4}{*}{ Anxiety } & $\mathrm{C} 1$ & Ref & & & & \\
\hline & $\mathrm{C} 2$ & $1.01(0.86-1.18)$ & $0.94(0.87-1.03)^{*}$ & $1.11(0.98-1.26)$ & $1.00(0.90-1.11)$ & $1.05(0.97-1.15)$ \\
\hline & $\mathrm{C} 3$ & $1.00(0.90-1.11)$ & $1.04(0.92-1.18)$ & $1.07(0.89-1.28)$ & $1.14(0.99-1.32)^{* *}$ & $1.07(0.99-1.16)^{* *}$ \\
\hline & $\mathrm{C} 4$ & $0.96(0.88-1.04)$ & $0.96(0.88-1.05)$ & $1.01(0.86-1.18)$ & $1.03(0.87-1.21)$ & $1.02(0.93-1.11)$ \\
\hline \multirow[t]{4}{*}{ Hostility } & $\mathrm{C} 1$ & Ref & & & & \\
\hline & $\mathrm{C} 2$ & $1.04(0.79-1.36)$ & $0.94(0.81-1.09)$ & $1.05(0.85-1.30)^{*}$ & $1.03(0.85-1.23)$ & $1.16(1.00-1.33)^{* * * *}$ \\
\hline & $\mathrm{C} 3$ & $1.04(0.87-1.23)$ & $1.01(0.82-1.25)^{* *}$ & $1.02(0.75-1.39)$ & $1.22(0.95-1.57)$ & $1.12(0.98-1.29)$ \\
\hline & $\mathrm{C} 4$ & $0.96(0.83-1.10)$ & $1.01(0.87-1.17)$ & $1.06(0.82-1.38)$ & $1.07(0.81-1.42)$ & $1.06(0.90-1.24)$ \\
\hline \multirow[t]{4}{*}{ Photic anxiety } & $\mathrm{C} 1$ & Ref & & & & \\
\hline & $C 2$ & $1.00(0.76-1.31)$ & $0.91(0.78-1.05)^{*}$ & $1.13(0.91-1.40)$ & $0.99(0.82-1.19)$ & $1.01(0.88-1.16)$ \\
\hline & C3 & $1.01(0.84-1.20)$ & $1.12(0.91-1.39)$ & $1.04(0.76-1.41)^{* *}$ & $1.25(0.98-1.60)$ & $1.13(0.98-1.30)^{* *}$ \\
\hline & $\mathrm{C} 4$ & $1.01(0.87-1.16)$ & $0.95(0.82-1.11)$ & $0.99(0.76-1.30)$ & $1.04(0.79-1.37)$ & $1.04(0.89-1.22)$ \\
\hline \multirow[t]{4}{*}{ Paranoid ideation } & $\mathrm{C} 1$ & Ref & & & & \\
\hline & $\mathrm{C} 2$ & $1.03(0.79-1.35)$ & $0.96(0.83-1.11)$ & $1.07(0.87-1.33)$ & $1.04(0.87-1.25)$ & $1.06(0.92-1.22)$ \\
\hline & C3 & $1.07(0.90-1.28)$ & $1.09(0.88-1.35)$ & $0.91(0.66-1.23)$ & $1.36(1.06-1.74)^{* * *}$ & $1.17(1.01-1.34)^{* * * *}$ \\
\hline & C4 & $0.96(0.83-1.11)$ & $1.02(0.88-1.19)$ & $1.02(0.78-1.33)$ & $1.19(0.90-1.57)$ & $1.01(0.86-1.18)$ \\
\hline \multirow[t]{4}{*}{ Psychoticism } & $\mathrm{C} 1$ & Ref & & & & \\
\hline & $C 2$ & $1.02(0.78-1.33)$ & $0.94(0.81-1.09)^{*}$ & $1.12(0.91-1.39)^{* *}$ & $1.06(0.88-1.27)$ & $1.06(0.92-1.22)$ \\
\hline & C3 & $1.03(0.87-1.23)$ & $1.02(0.82-1.26)$ & $0.97(0.71-1.32)$ & $1.31(1.02-1.68)^{* *}$ & $1.12(0.98-1.29)$ \\
\hline & C4 & $0.97(0.841 .12)$ & $1.00(0.85-1.16)$ & $1.02(0.78-1.32)$ & $1.13(0.86-1.50)$ & $1.02(0.87-1.19)$ \\
\hline \multirow[t]{4}{*}{ Additional items } & $\mathrm{C} 1$ & Ref & & & & \\
\hline & $C 2$ & $1.16(0.89-1.52)$ & $0.93(0.81-1.08)$ & $1.10(0.89-1.35)^{*}$ & $0.98(0.82-1.18)$ & $1.09(0.94-1.25)$ \\
\hline & $\mathrm{C} 3$ & $1.07(0.89-1.27)$ & $1.06(0.85-1.30)^{*}$ & $1.04(0.76-1.41)$ & $1.13(0.89-1.45)^{*}$ & $1.17(1.02-1.35)^{* *}$ \\
\hline & $\mathrm{C} 4$ & $0.99(0.86-1.14)$ & $0.97(0.83-1.13)$ & $1.01(0.78-1.31)$ & $1.05(0.80-1.38)$ & $1.07(0.92-1.25)$ \\
\hline
\end{tabular}

$p<0.05^{*}$ 
cluster 3 in factor 5 , the ORs and CIs were1. 1.16(1.00$1.33), 12(0.98-1.29), 1.06(0.90-1.24)$ for cluster 2 ,cluster3 and cluster 4. In Photic anxiety, the ORs and CIs were 1.13(0.91-1.40), 1.04(0.76-1.41), 0.99(0.76-1.30) for cluster 2, cluster 3 and cluster 4 in factor 5. In Psychoticism, the ORs and CIs were 1.06(0.88-1.27), $1.31(1.02-1.68), 1.13(0.86-1.50)$ for cluster 2 , cluster 3 and cluster 4 in factor 4 , respectively.

In the first model, we compared participants with physical education class times of the ORs and 95\% CIs were $0.75(0.57-1.00), 0.86(0.72-1.03)$ and $0.88(0.76-$ 1.02) (Table 5). The result show that screen time is significantly associated with PE class time in cluster 2 . In the second model, we adjusted a variable and added physical education class time. The result show that cluster 2 and cluster 3 in factor 1 (screen time) are very significantly associated with at lunch time. In the third model, we added physical activity at lunch time, cluster 4 in factor 4 (bully behaviors) is significantly associated with after school. In the fourth model, the results show that cluster 4 in factor 3 (smoking) and factor 4 (bully behaviors) are significantly associated with evening time. In the fifth model, the result is almost same as the fourth model.

\section{Discussion}

The purpose of this study was to examine the association of clustered risk behaviors with adolescent mental health and physical activity, and identify to what extent the clustering of various risk behaviors is associated with psychological health and physical activity in Chinese adolescents. The research evaluates a broad spectrum of risk behaviors associated with mental health and physical activity in boys and girls. The results showed that risk behavior may have multiple clustering effects on mental health, which consistent with the transactional theory of stress and coping risk and resilience issues [19]. Under different variables, the relationship between risk behavior and mental health is different. In reference to cluster and factor analysis, it was found that specific risk behavior is related to specific mental disorders, including psychosomatic, obsessive-compulsive, intrinsic sensitivity, anxiety, hostility, psychosis and other mental disorders. This study illustrates the significant difference of risk health behaviors and mental health issues, except for physical activity, between boys and girls. Consistent with previous studies, boys are more likely to participate in risk behavior than girls. Girls are more likely than boys to have feelings of academic pressure, and boy are more

Table 5 Odd ratios (ORS of the cluster risk behavior and physical activity from ordered logic model)

\begin{tabular}{|c|c|c|c|c|c|c|}
\hline & & $\mathrm{F} 1$ & F2 & F3 & F4 & F5 \\
\hline \multirow[t]{4}{*}{ Model $^{1}$} & $\mathrm{C} 1$ & Ref & & & & \\
\hline & $\mathrm{C} 2$ & $0.75(0.57-1.00)^{* * *}$ & $0.99(0.85-1.57)$ & $1.06(0.85-1.33)$ & $0.74(1.08-1.32)$ & $0.99(0.85-1.15)$ \\
\hline & $\mathrm{C} 3$ & $0.86(0.72-1.03)$ & $0.75(0.60-0.95)$ & $1.07(0.76-1.50)$ & $0.98(0.76-1.27)$ & $0.82(0.71-0.95)^{* *}$ \\
\hline & C4 & $0.88(0.76-1.02)$ & $1.03(0.87-1.20)$ & $1.34(1.01-1.78)$ & $0.93(0.7-1.24$ & $1.00(0.85-1.18)$ \\
\hline \multirow[t]{4}{*}{ Model $^{2}$} & $\mathrm{C} 1$ & Ref & & & & \\
\hline & $\mathrm{C} 2$ & $1.51(1.13-2.02)^{* *}$ & $1.00(0.86-1.16)$ & $1.02(0.82-1.27)$ & $0.89(0.74-1.08)$ & $0.95(0.81-1.10)$ \\
\hline & $\mathrm{C} 3$ & $1.30(1.08-1.57)^{* *}$ & $0.77(0.62-0.97)^{* *}$ & $1.03(0.74-1.43)$ & $0.83(0.63-1.08)$ & $1.08(0.93-1.25)$ \\
\hline & $\mathrm{C} 4$ & $1.12(0.96-1.31)$ & $1.02(0.87-1.20)$ & $1.37(1.04-1.81)^{* *}$ & $0.88(0.66-1.18)$ & $1.01(0.85-1.20)$ \\
\hline \multirow[t]{4}{*}{ Model $^{3}$} & $\mathrm{C} 1$ & Ref & & & & \\
\hline & $\mathrm{C} 2$ & $1.13(0.84-1.51)$ & $1.02(0.87-1.2)$ & $0.91(0.72-1.15)$ & $0.96(0.79-1.16)$ & $0.93(0.80-1.09)$ \\
\hline & C3 & $1.11(0.92-1.34)$ & $0.98(0.78-1.22)$ & $1.23(0.88-1.72)$ & $0.84(0.65-1.10)$ & $1.10(0.95-1.28)$ \\
\hline & $\mathrm{C} 4$ & $0.99(0.85-1.16)$ & $0.99(0.84-1.17)$ & $1.17(0.88-1.56)$ & $0.73(0.54-0.99)^{* *}$ & $1.07(0.90-1.27)$ \\
\hline \multirow[t]{4}{*}{ Model ${ }^{4}$} & $\mathrm{C} 1$ & Ref & & & & \\
\hline & $\mathrm{C} 2$ & $1.18(0.89-1.58)^{*}$ & $1.03(0.88-1.20)$ & $1.1(0.87-1.38)$ & $0.98(0.81-1.19)$ & $1.01(0.86-1.17)$ \\
\hline & C3 & $0.94(0.78-1.14)$ & $0.87(0.69-1.09)$ & $1.19(0.85-1.67)$ & $1.09(0.84-1.42)$ & $1.13(0.97-1.30)$ \\
\hline & C4 & $0.9(0.77-1.05)$ & $0.98(0.83-1.15)$ & $1.06(0.79-1.40)^{* *}$ & $0.85(0.63-1.15)^{* *}$ & $0.97(0.82-1.116)$ \\
\hline \multirow[t]{4}{*}{ Model $^{5}$} & C1 & Ref & & & & \\
\hline & $\mathrm{C} 2$ & $1.03(0.77-1.39)$ & $1.04(0.89-1.23)$ & $1.12(0.89-1.41)$ & $1.05(0.87-1.28)$ & $1.01(0.86-1.18)$ \\
\hline & C3 & $0.86(0.73-1.07)$ & $1.02(0.81-1.28)$ & $1.15(0.82-1.62)$ & $1.04(0.80-1.36)$ & $1.22(1.05-1.42)^{*}$ \\
\hline & $\mathrm{C} 4$ & $0.91(0.78-1.1)$ & $0.94(0.79-1.11)$ & $1.20(0.91-1.60)^{* *}$ & $0.84(0.62-1.14)^{* *}$ & $1.03(0.87-1.22)$ \\
\hline
\end{tabular}

Logic regression showed the relationship between physical activity and risk behavior in the 6 models in terms of the different adjusted variables. We added an adjusted variable for each model, respectively, except for model 1 
likely to participate in smoking, alcohol abuse. The girls are more likely to be bullied in school, bullied electronically, feel sad or hopeless, and to try smoking [32].

Factor analysis identified five main factor patterns in this study:1) problematic screen time use; 2) use of alcohol; 3) smoking; 4) bully behavior; 5) sedentary behavior. Four clusters in five factors were distinguished in that four clusters (1-4) in factor 1 (screen time) and factor 4 (bully) have relatively normal all-behavioral pattern scores, which means that screen time and bullying/electronically bullied Chinese students is not a very serious problem, mainly because high school students are not allowed to bring cell phones/iPads on campus, which also reduced electrically bullied reduced greatly. This study demonstrate that alcohol use, smoking and sedentary behavior have significant effects on adolescent health. Factor 5 contains two high cluster and one medium cluster, which means that sedentary behavior significantly affects adolescent health in China.

Regarding problematic screen time use and mental health, this study found that the screen time is not associated with psychological health problems after monitoring for its obsessive component in the regression analyses, as is consistent with previous study $[13,28,36]$. This illustrates the position of multi-behavioral factors and clustering analyses when considering behavioral and mental health risk in adolescents as well as the hazard of overemphasizing effects when exploring these associations in a solitary study [36]. However, some evidences associate screen time with mental health problems [31, 36-41]. Those studies indicate a U-shaped relationship between screen time behaviors and psychological problems [40, 41], in which a certain amount of time gone through a certain status (duration/intensity), the screen time behavior becomes problematic and associates with decreased mental health. Additionally, new smart phones/games/ websites are developing rapidly and make it hard to properly scrutinize the relationship of screen-time behavior to mental health problems.

The association between use of alcohol and psychological problems is quite controversial. Some studies have indicated no direct relationship with light, moderate and heavy drinkers [42] who have associated with depression and anxiety. Some studies found that alcohol abstainers may develop higher levels of anxiety and depression compared to those who are not alcohol abstainers [43]. However, it is difficult to elucidate these results to sustain the beneficial impacts of moderate alcohol consumption. Sociodemographic characteristics (e.g., gender, age, education, working status), tobacco, and BMI were considered as control variables, but the U-shaped relation may not illustrate the association between alcohol use and psychological problems. In a different analysis, the positive association between moderate alcohol consumption and psychological problems may be impacted by sociodemographic features or unhealthy lifestyle and not triggered by the alcohol use itself [44]. The present study shows that alcohol consumption influences psychological problems in specific factor-clusters, such as obsessive-compulsive disorder, interpersonal sensitivity, hostility, depression, anxiety. Although previous evidence regarding alcohol use and psychological problems was diverse [45]. This study presumed that more frequent alcohol consumption would cause mental health problems. Our proposition was tested only in Chinese adolescents. Some research has demonstrated that students drink more frequently and present greater psychological well-being, which may be explained by those students drinking alcohol on a regular basis rather than binge-drinking, or displaying other sociodemographic features, such as higher socioeconomic status, more social activity and better personal or familial relationships [46].

Tobacco use is recognized as a risk behavior for mental health $[46,47]$. Our assumption regarding the association of smoking with mental health was supported in this study. Smoking in Chinese students was a positive predictor of psychological problems related to photic anxiety, psychoticism, obsessive- compulsive disorder, and interpersonal sensitivity. Some studies have found that people who quit smoking undergo a significant decline in symptoms of stress, depression and anxiety, and a rise in life satisfaction and emotional well-being, which contrasts with continuing smokers [48, 49]. Tobacco use is associated with symptoms of depression during early adolescence [50]. Youth smokers with depression and anxiety may develop a tobacco addiction in early adulthood [51]. Further promoting smoking cessation programs might assist more adolescents to stop tobacco use and thereby not only enhance physical health, but also their psychological well-being [52].

Evidence demonstrates that bullying has become a serious and pervasive problem, and bullied teenagers are more vulnerable to psychological harm in their lives [53]. The experiences of being bullied or bullying others are associated with psychological problems in adolescence [13]. This study shows that bullying behaviors are significantly associated with interpersonal sensitivity, paranoid ideation, psychoticism, and anxiety in Chinese adolescents. The previous study demonstrated that children and young people who have been bullied will often suffer from long-term mental health problems, such as social isolation, depression, loneliness, anxiety, and suicidal ideation. Perpetrators of bullying also experience a heightened risk of psychological problems such as depression, anxiety, and antisocial behavior [54]. In addition, recent rapid advances in electronic communication technologies also greatly increase the likelihood of 
this factor emerging. Determining the factors related to bullying is helpful in formulating effective intervention measures for school adolescent bullying [55]. Overall, adolescents with mental health struggles have been recognized as victims of bullying more often, are more frequent game players and compulsive internet users and have more habits of physical inactivity, unhealthy diet and smoking than those without psychosocial problems [56].

Chinese high school students have serious sedentary behavior because they face heavy schoolwork burdens which require total sitting times of $12-13 \mathrm{~h}$ or more. If we count typical student daily activities including 8-h class study, 8$\mathrm{h}$ sleep, 1.5-h three meals, 1 -h break time, then the remaining $5.5 \mathrm{~h}$ are spent in sedentary behavior [57]. We compare to South Koreans [58] at $8.9 \mathrm{~h} /$ day, Americans [53] at $7.5 \mathrm{~h} /$ day, and Canadians [59] at $9.1 \mathrm{~h} /$ day, which includes all their daily sedentary behavior: homework, watching TV, internet, parties etc. Most of the sedentary behavior of Chinese adolescents is education-related, including after-school homework and tutoring, reflecting a critical education problem in China. Homework and tutoring occupy most of the sitting time that seems to reflect characteristic of Chinese adolescents. In contrast, screen-related sedentary behavior comprises most of the sitting time of foreign children and adolescents [60].

This study suggests that sedentary behavior is associated with somatization, obsessive-compulsive disorder, depression, anxiety, hostility, photic anxiety, and paranoid ideation. Consistent with previous research, reduced sedentary behavior and increased physical activity may mitigate various psychological problems, including low self-esteem, depression, inappropriate social behaviors and poor emotional well-being among adolescents [61] and perceived stress [21]. Although some researchers have found negative health consequences of sedentary behavior, the association between mental health and sedentary behavior is inconsistent [62]. A systematic review showed that there was limited available evidence demonstrating that student sedentary behaviors are significantly related to mental health [63]. Students participating in physical activity during school time may present better physical, psychosocial, and cognitive health compared to those who were sedentary during any school physical activity opportunities [64]. This study demonstrates that physical activity significantly affects sedentary behavior and screen time and reduces bully behavior. Chinese high school students face their greatest challenge in the college entrance examination. This study showed that increased sedentary time results in a significant decrease of physical activity as well as physical fitness, which reflects the reality of school-based physical activity. Increasing physical activity can reduce sedentary behaviors, such as watching TV and video gaming $[65,66]$. Physical activity can be used to design effective intervention programs to change unhealthy habits and risk behaviors of adolescents and promote their physical health [67]. Some studies demonstrate that adolescents who are actively encouraged to participate in more exercise will reduce screen time, develop friendships and increase their emotional well-being [68]. Physical activity has protective and indirect effects on smoking and alcohol use in adolescents [29, 69]. Some research indicates that educating adolescents to avoid using alcohol and to maintain proper healthy diet habits does not have a more significant impact on fitness than does encouraging them to participate in sufficient physical activity [70].

\section{Strength and limitation}

There are several strengths and weaknesses in this study. This study is the first time to focus on clusters of risk behaviors and factors that may be associated with mental health and physical activity in Chinese adolescents. Previous studies have investigated subcategories of risk behaviors, but this study explored the association between a more comprehensive set of behaviors and mental health. Integrating clusters construction and factor analyses were utilized in this study. The strong factor loadings and significant association were identified. Validated survey instruments were utilized to collect data on physical activity, risk behaviors and mental health. The response rate of 95.8\% exist not response bias. The limitation of the current study is cross-sectional investigation, it was not possible to define the temporal relationship between cause and consequence, but our approach allowed us to assess relationship between risk behavior, mental health and physical activity. However, the relationship needs to be further verified by behavior intervention experiments and physiological mechanisms. In addition, this study chose a sample of high school students from the Shandong province in China, thus the results may not be generalizable to all of China. The relative lack of sociodemographic variables might also limit the comprehensiveness of some outcomes.

\section{Conclusion}

This study finds that a specific behavior cluster has significant impact on mental health and physical activity among adolescents. This study shows that integrating risk behaviors cluster with factors can be employed to target high-risk adolescents who have poor physical and psychosocial health. The findings of this study suggest that more effective and feasible school intervention programs can be designed to promote adolescent healthrelated behavior in terms of those pathways. However, examination of the clustering of risk behaviors should further explore determinants across diverse types of health behaviors for adolescent intervention programs. 


\section{Acknowledgements}

This work was supported by the Ministry of Science and Technology of China. We would like to thank all the subjects who participated in the study.

\section{Authors' contributions}

$X Y$ was the Principal Investigator who designed the study, collected the data and drafted the manuscript. ZL and WQ collected the data and drafted the manuscript. YY and NY analyzed the data and revised the manuscript. XD and BW was the project coordinator who designed the study, collected the data. The author(s) read and approved the final manuscript.

\section{Funding}

This work was supported by $2015 \mathrm{FY} 111600$ from the Ministry of Science and Technology of China.

\section{Availability of data and materials}

The datasets during and/or analysed during the current study available from the corresponding author on reasonable request.

\section{Ethics approval and consent to participate}

The research was approved by the ethical committees of Shandong University (20180517).

\section{Consent for publication}

Not applicable.

\section{Competing interests}

Authors declare no potential conflict of interest for this study.

\section{Author details}

'Department of Sport and Health, School of Physical Education, Shandong University, Jinan 250061, China. ${ }^{2}$ Department of Science and Technology, Shandong Institute of Commerce and Technology, Jinan 250103, China. ${ }^{3}$ Department of Human Performance and Health Education, Western Michigan University, Kalamazoo, Ml 49008, USA. ${ }^{4}$ Department of Kinesiology, College of Health Science, University of Wisconsin- Milwaukee, Milwaukee, WI 53201, USA. ${ }^{5}$ School of Public Health, Shandong University, Jinan 250061, Shandong, China.

Received: 8 February 2020 Accepted: 30 June 2020

Published online: 03 July 2020

\section{References}

1. Achhab YE, Ammari AE, Kazdouh H, Najdi A, Berraho M, Tachfouti N, Lamr $D$, et al. Health risk behaviors amongst school adolescents: protocol for a mixed methods study. BMC Public Health. 2016;16:1209.

2. Busch V, Robertus J, Leeuw J. Unhealthy behaviors in adolescents: multibehavioral associations with psychosocial problems. Int J Behav Med. 2014;21:439-46.

3. Dake JA, Price JH, Telljohann SK. The nature and extent of bullying at school. J Sch Health. 2003;73:173-80.

4. Bolinder G, Alfredsson L, Englund A, De Faire U. Smokeless tobacco use and increased cardiovascular mortality among Swedish construction workers. Am J Public Health. 1994;84(3):399-404.

5. Augustine J. Unhealthy diet. EMS World. 2013;42:16-8 20.

6. Hildreth CJ. High levels of physical inactivity and sedentary behaviors among US immigrant children and adolescents: the journal of the American medical association. Jama. 2008;300:1633.

7. Woodin EM, Caldeira V, Sotskova A, Galaugher T, Lu M. Harmful alcohol use as a predictor of intimate partner violence during the transition to parenthood: interdependent and interactive effects. Addict Behav. 2014;39: 1890.

8. CDC. Division of Adolescent and School Health. YRBSS Questionnaire 2017. https://www.cdc.gov/healthyyouth/data/yrbs/questionnaires.htm.

9. World Health Organization. 2008-2013 action plan for the global strategy for the prevention and control of noncommunicable diseases. Geneva: World Health Organization; 2011.

10. Moon SS, Karlson A, Kim YJ. Peer victimization and adolescent suicide: the mediating effect of risk behaviors: C \& A C \& A. Child Adolesc Soc Work J. 2015;32:257-68
11. Rosario M, Corliss HL, Everett BG, Reisner SL, Austin SB, Buchting FO, Birkett M. Sexual orientation disparities in cancer-related risk behaviors of tobacco, alcohol, sexual behaviors, and diet and physical activity: pooled youth risk behavior surveys. Ameri J Pub Health. 2014;104:245-23.

12. Ajibade PB. Health risk behaviors of black male college students: seat belt use, smoking, and obesity status. ABNF J. 2010;21:85-9.

13. Long MN, Dowdell EB. Online and health risk behaviors in high school students: an examination of bullying. Pediatr Nurs. 2018;44:223-8.

14. Clark T, Fleming T, Bullen P, Crengle S, Denny S, Dyson B, Peiris-John R, Robinson E, Rossen F, Sheridan J, et al. Health and well-being of secondary school students in New Zealand: trends between 2001, 2007 and 2012. J Paediatr Child Health. 2013;49:925-34.

15. Huang DYC, Lanza HI, Murphy DA, Hser YI. Parallel development of risk behaviors in adolescence: potential pathways to co-occurrence. Int J Behav Dev. 2012:36:247-25715.

16. Alamian A, Paradis G. Clustering of chronic disease behavioral risk factors in Canadian children and adolescents. Prev Med. 2009:48:493-9.

17. Mistry R, McCarthy WJ, Yancey AK, Lu Y, Patel M. Resilience and patterns of health risk behaviors in California adolescents. Prev Med. 2009:48:291-7.

18. Wijnhoven TMA, van Raaij JMA, Yngve A, Sjöberg A, Kunesová M, Duleva V, et al. WHO European childhood obesity surveillance initiative: health-risk behaviors on nutrition and physical activity in 6-9-year-old schoolchildren. Public Health Nutr. 2015;18:3108-24.

19. Hobfoll S, Johnson R, Ennis N, Jackson A. Resource loss, resource gain, and emotional outcomes among inner city women. J Pers Soc Psychol. 2003;84: 632-43.

20. Banou E, Hobfoll S, Trochelman R. Loss of resources as mediators between interpersonal trauma and traumatic and depressive symptoms among women with cancer. J Health Psychol. 2009;14:200-14.

21. Cheng C, Lau H, Chan M. Coping flexibility and psychological adjustment to stressful life changes: a meta-analytic review. Psychol Bull. 2014;140:1582607.

22. Rzeszutek, M. , Pięta, M, \& Huzar M. (2019). Profiles of resources and body image in health and illness: a comparative study among females with rheumatoid arthritis, females with breast cancer and healthy controls. Brain Behav, e01488. https ://doi.org/10.1002/brb.

23. Tavolacci MP, Ladner J, Grigioni S, et al. Prevalence and association of perceived stress, substance use and behavioral addictions: a cross-sectional study among university students in France, 2009-2011[J]. BMC Public Health. 2013;13(1):1-8.

24. Hoare E, Milton K, Foster C, Allender S. The associations between sedentary behavior and mental health among adolescents: a systematic review. Int J Behav Nutr Phys Act. 2016;13:108

25. Glick P, Khammash U, Shaheen M, Brown R, Goutam P, et al. Perceived peer norms, health risk behaviors, and clustering of risk behaviors among Palestinian youth. PLoS One. 2018;13:e0198435.

26. Malhotra A, Noakes T, Phinney S. It is time to bust the myth of physical inactivity and obesity: you cannot outrun a bad diet. Br J Sports Med. 2015; 49:967-8.

27. Mahtani KR, McManus J, Nunan D. Physical activity and obesity editorial: is exercise pointless or was it a pointless exercise? Br J Sports Med. 2015:49: 969-70.

28. Kremer P, Elshaug C, Leslie E, Toumbourou JW, Patton GC, Williams J. Physical activity, leisure-time screen use and depression among children and young adolescents. J Sci Med Sport. 2014;17:183-7.

29. Daniel R, Janet A. Physical activity, global physical self-concept, and adolescent smoking. Ann Behav Med. 2005:30:251-9.

30. Lemmens JS, Valkenburg PM, Peter J. Psychosocial causes and consequences of pathological gaming. Comput Hum Behav. 2011;27:144-52.

31. Zhang YY, Lei YT, Song Y, Lu RR, Duan JL, Prochaska JJ. Gender differences in suicidal ideation and health-risk behaviors among high school students in Beijing, China. J Glob Health. 2019:9(9):010604.

32. Yang Y, Qi Y, Cui Y, Li B, Zhang Z, Zhou Y, et al. Emotional and behavioral problems, social competence and risk factors in 6-16-year-old students in Beijing, China. PLoS One. 2019;14(10):e0223970.

33. Drogatis LR, Cleary P. Confirmation of the dimensional structure of the SCL90: a study in construct validation. Psychology. 1977;33:981-9.

34. Feng Z, Zhang D. Study on the validity of the symptom check-List-90 of Chinese version. Aata Acad Med Militaris Tertiae. 2001;4:481-3.

35. Chen S, Li L. Re-testing reliability, validity and norm applicability of SCL-90. Chin J Nerv Ment Dis. 2003;5:323-7. 
36. Zabinski MF, Norman GJ, Sallis JF, Calfas KJ, Patrick K. Patterns of sedentary behavior among adolescents. Health Psychol. 2007;26:113-20.

37. Tonioni F, D'Alessandris L, Lai C, Martinelli D, Corvino S, et al. Internet addiction: hours spent online, behaviors and psychological symptoms. Gen Hosp Psychiatry. 2012;34:80-7.

38. Cao H, Sun Y, Wan Y, Hao J, Tao F. Problematic Internet use in Chinese adolescents and its relation to psychosomatic symptoms and life satisfaction. BMC Public Health. 2011;11:802.

39. Holtz P, Appel M. Internet use and video gaming predict problem behavior in early adolescence. J Adolesc. 2011;34:49-58.

40. Van Rooij AJ, Schoenmakers TM, Jansz J. A short overview of scientific research into the effects of videogames. Zoetermeer: Kennisnet; 2010.

41. Belanger RE, Akre C, Berchtold A, Michaud PA. A u-shaped association between intensity of internet use and adolescent health. Pediatrics. 2011; 127:e330-5.

42. Rodgers B, Korten AE, Jorm AF, Christensen H, Henderson S, Jacomb PA. Risk factors for depression and anxiety in abstainers, moderate drinkers and heavy drinkers. Addiction. 2000;95:1833-45.

43. Skogen JC, Harvey SB, Henderson M, Stordal E, Mykletun A. Anxiety and depression among abstainers and low-level alcohol consumers. The Nord Trøndelag health study. Addiction. 2009;104:1519-29.

44. Massin S, Kopp P. Is life satisfaction hump-shaped with alcohol consumption? Evidence from Russian panel data. Addict Behav. 2014;39: $803-10$

45. Velten J, Bieda A, Scholten S, Wannemüller A, Margraf J. Lifestyle choices and mental health: a longitudinal survey with German and Chinese students. BMC Public Health. 2018;18:632.

46. Lien L, Satatun Å, Heyerdahl S, Søgaard AJ, Bjertness E. Is the relationship between smoking and mental health influenced by other unhealthy lifestyle factors? Results from a 3-year follow-up study among adolescents in Oslo, Norway. J Adole Health. 2009;45:609-17.

47. Taylor G, McNeill A, Girling A, Farley A, Lindson-Hawley N, Aveyard P. Change in mental health after smoking cessation: systematic review and meta-analysis. BMJ. 2014;348:1151.

48. Weinhold D, Chaloupka FJ. Smoking status and subjective well-being. Tob Control. 2017;26:195-201

49. Tjora T, Hetland J, Aaroe LE, Wold B, Wiium N, Oeverland S. The association between smoking and depression from adolescence to adulthood. Addiction. 2014;109:1022-30.

50. McKenzie M, Olsson CA, Jorm AF, Romaniuk H, Patton GC. Association of adolescent symptoms of depression and anxiety with daily smoking and nicotine dependence in young adulthood: findings from a 10-year longitudinal study. Addiction. 2010;105:1652-9.

51. Hutton HE, Wilson LM, Apelberg BJ, Tang EA, Odelola O, et al. A systematic review of randomized controlled trials: web-based interventions for smoking cessation among adolescents, college students, and adults. Nicotine Tob Res. 2011;13:227-38.

52. Yen C, Yang P, Wang P, Lin H, Liu T, Wu Y, et al. Association between school bullying levels/types and mental health problems among Taiwanese adolescents. Compre Psych. 2014;55(3):405-13.

53. Cowie H, Myers CA. School bullying and mental health: risks, intervention and prevention (1st Ed). London: CRC press, Taylor \& Francis Group; 2017.

54. Wan Ismail WS, Nik Jaafar NR, Sidi H, Midin M, Shah SA. Why do young adolescents bully? Experience in Malaysian schools. Compre Psychy. 2014; 55:S114-20.

55. Kozasa S, Oiji A, Kiyota A, Sawa T, Kim SY. Relationship between the experience of being a bully/victim and mental health in preadolescence and adolescence: a cross-sectional study. Ann General Psychiatry. 2017;16:37.

56. Guo Q, Wang X. The patterns of physical activity and sedentary behavior in Chinese children and adolescents. China Sport Sci. 2017;7:17-29.

57. Lee EY, Carson V, Jeon JY, et al. Prevalence of physical activity and sitting time among south Korean adolescents: results from the Korean national health and nutrition examination survey 2013. Asia Pac J Public Health. 2016;28:498

58. Carson V, Staian AE, Taiano AE, Katzmarzyk PT. Physical activity, screen time, and sitting among us adolescents. Pediatr Exerc Sci. 2015;27:151-9.

59. Colley RC, Gariguet D, Janssen I, et al. Physical activity of Canadian adults: accelerometer results from the 2007 to 2009 Canadian health measures survey. Health Rep. 2011;22:7-14.

60. Hoffer WR, Mckenzie T, Sallis JF, et al. Parental provision of transportation for adolescent physical activity. Am J Prev Med. 2001;21:48-51.
61. Cliff DP, Hesketh KD, Vella SA, Hinkley T, Tsiros MD, et al. Objectively measured sedentary behavior and health and development in children and adolescents: systematic review and meta-analysis. Obes Rev. 2016;17:330-44.

62. Biddle SJ, Asare M. Physical activity and mental health in children and adolescents: a review of reviews. Bri J Sports Med. 2011;45:886-95.

63. Lubans D, Richards J, Hillman C, Faulkner G, Beauchamp M, et al. Physical activity for cognitive and mental health in youth: a systematic review of mechanisms. Pediatrics. 2016;138:e20161642.

64. Gu XM, Keller MJ, Weiller-Abels HK, Zhang T. The roles of physical activity and sedentary behavior on Hispanic children's mental health: a motor skill perspective. Qual Life Res. 2018;27:185-93.

65. Väistö J, Eloranta A, Viitasalo A, Tompuri T, Lintu N, et al. Physical activity and sedentary behavior in relation to cardiometabolic risk in children: crosssectional findings from the physical activity and nutrition in children (PANIC) study. Int J Behav Nutr Phys Act. 2014;11:55.

66. Pearson N, Braithwaite RE, Biddle SJH, et al. Associations between sedentar behavior and physical activity in children and adolescents: a meta-analysis. Obes Rev. 2014;15:666-75.

67. Dong J, Zhang S, Li X, Yu Y, Hu S, Sun J, et al. Physical activity, a critical exposure factor of environmental pollution in children and adolescents health risk assessment. Int J Environ Res Public Health. 2018;15:176.

68. Rangul V, Bauman A, Holmen TL, Midthjell K. Is physical activity maintenance from adolescence to young adulthood associated with reduced CVD risk factors, improved mental health and satisfaction with life: the HUNT study, Norway. Int J Behav Nutr Phys Act. 2012;9:144.

69. Werch C, Moore M, DiClemente CC, Owen DM, et al. A sport-based intervention for preventing alcohol use and promoting physical activity among adolescents. J Sch Health. 2003;73:380-8.

70. Garden T, Avery F, Monèm J, et al. Profiles of physical Fitness risk behaviors in school adolescents from the ASSO project: A latent class analysis. Int J Environ Res Public Health. 2018;15:1933.

\section{Publisher's Note}

Springer Nature remains neutral with regard to jurisdictional claims in published maps and institutional affiliations.

\section{Ready to submit your research? Choose BMC and benefit from:}

- fast, convenient online submission

- thorough peer review by experienced researchers in your field

- rapid publication on acceptance

- support for research data, including large and complex data types

- gold Open Access which fosters wider collaboration and increased citations

- maximum visibility for your research: over $100 \mathrm{M}$ website views per year

At BMC, research is always in progress.

Learn more biomedcentral.com/submissions 